\title{
Penyebaran Spesialis Anak di Indonesia Tahun 2004: Implikasinya Terhadap Kebijakan Kesehatan dan Pendidikan
}

\author{
Yati Soenarto, Laksono Trisnantoro, Anis Fuad
}

\begin{abstract}
Komposisi penyebaran tenaga dokter spesialis anak ( $\mathrm{SpA}$ ) di tingkat propinsi di Indonesia masih belum merata. Distribusi penyebaran tenaga spesialis ini hampir $70 \%$ berpusat di Jawa dan Bali, bahkan tercatat di beberapa propinsi lain yang tidak memiliki satupun tenaga SpA. Tulisan ini menyajikan distribusi penyebaran SpA di setiap di propinsi di Indonesia dan proporsi pertumbuhan $\mathrm{SpA}$ berdasarkan jenis kelamin. Dalam tulisan ini juga didiskusikan beberapa implikasi terhadap kebijakan yang mungkin dapat dijadikan pertimbangan dalam pengembangan model distribusi tenaga SpA.
\end{abstract}

Kata kunci: dokter spesialis anak, pola penyebaran, proporsi pertumbuhan, implikasi kebijakan

$\mathrm{V}$ isi Ikatan Dokter Anak Indonesia (IDAI) ialah pada tahun 2010 terbina komunitas spesialis anak dengan kemampuan profesional bertaraf internasional dan mampu berperan aktif dalam tercapainya hak dan perlindungan anak di Indonesia dalam pembangunan manusia Indonesia seutuhnya untuk membentuk masyarakat madani

\footnotetext{
Alamat korespondensi:

Dr. S. Yati Soenarto, PhD, SpA(K).

Anggota Kolegium Ilmu Kesehatan Anak Indonesia Bagian Ilmu Kesehatan Anak FK UGM/RS Dr. Sardjito Jl. Kesehatan No. 1, Sekip Utara, Yogyakarta 55284.

Telp. (0274) 587333 ext 219/ Hp 0811256011 Fax. (0274) 583745

Email: yatisoenarto@yahoo.com
}

Prof. Dr. Laksono Trisnantoro, MSc, PhD, Anis Fuad, Sked, MSc Bagian IKM Fakultas Kedokteran UGM Jl. Farmako, Sekip Utara, Yogyakarta..

Telp. (0274) 549425 Fax. (0274) 547490

Email: trisnantoro@yahoo.com dan fuadanis@yahoo.com dalam wadah bangsa yang maju, mandiri, sejahtera, dan berkeadilan. ${ }^{1}$ Salah satu indikator pelayanan kesehatan anak berkolerasi dengan penyebaran jumlah dokter Spesialis Anak (SpA) di seluruh lapisan masyarakat. Oleh karena itu, perlu disikapi dan dikaji beberapa alternatif sebagai dasar pertimbangan pengambilan keputusan oleh semua pihak terkait. Pendistribusian SpA, khususnya dalam upaya pemerataan penyebaran secara geografis, perlu mempertimbangkan beberapa faktor yang mempengaruhinya. ${ }^{2}$ Apalagi konsep desentralisasi termasuk isu reformasi kesehatan telah banyak diajukan untuk peningkatan sektor pelayanan publik. $^{3}$

Kajian ini bertujuan untuk (1) membahas penyebaran dokter anak, (2) mengkaji pertumbuhan dokter anak dikaitkan dengan jenis kelamin; dan (3) mengkaji skenario serta implikasi kebijakannya, dengan menggunakan data cross-sectional dan data sekunder dari (1) register anak di IDAI dan (2) data dari Departemen Keuangan dan Badan Pusat Statistik Jakarta. 


\section{Distribusi komposisi penyebaran dokter SpA}

Untuk mengetahui penyebaran dokter Spesialis Anak (SpA) di Indonesia, dilakukan analisis database IDAI pada bulan Juni 2005. Data menunjukkan terdapat $1821 \mathrm{SpA}$, termasuk yang sudah meninggal dunia. Register pertama adalah almarhum Prof. Dr. Sugiri, Sp.A dari Bandung sedangkan register terakhir tercatat atas nama dr. IB Eka Utami Wija, SpA dari Jakarta Selatan yang lulus PSSp1IKA (Program Studi
Spesialis1 Ilmu Kesehatan Anak) pada tahun 2004. Dugaan bahwa sebagian besar SpA terkonsentrasi di pulau Jawa dan Bali, ternyata memang benar. Hampir $70 \%$ dari seluruh penyebaran SpA terpusat di JawaBali yang berpenduduk 118 juta, atau 56\% dari seluruh populasi di Indonesia. Rasio komposisi penyebaran SpA tertinggi adalah di DKI Jakarta, disusul DI Yogjakarta, Sulawesi Utara dan Bali. Bahkan, menurut database IDAI di propinsi Bengkulu dan Maluku Utara tidak tercatat adanya SpA. (Gambar 1 dan 2)

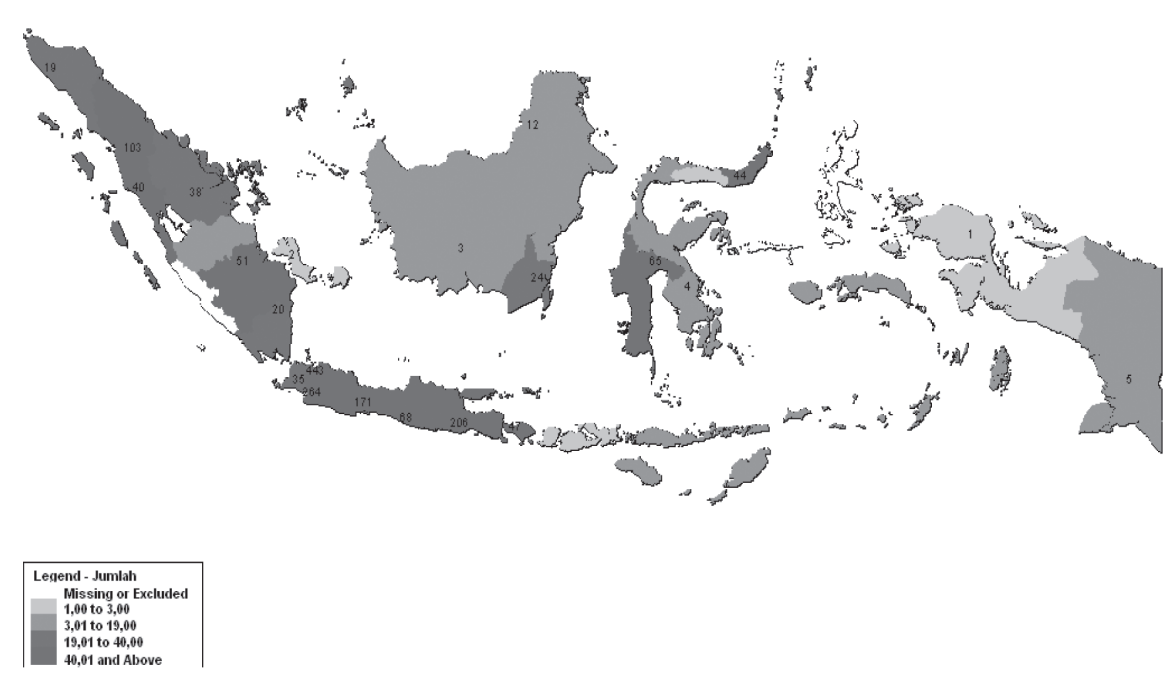

Gambar 1. Distribusi SpA di seluruh wilayah Indonesia berdasarkan jumlah absolut di masing-masing propinsi (Sumber: database IDAI)

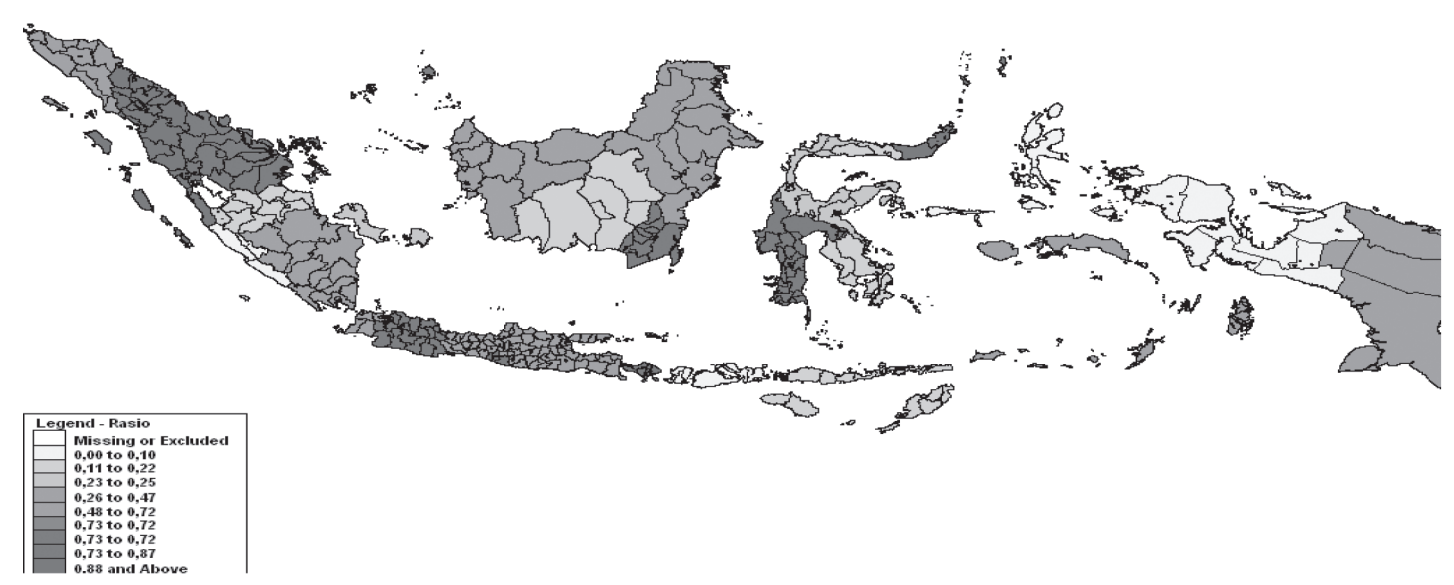

Gambar 2. Rasio SpA per 100.000 penduduk menurut propinsi (sumber: database IDAI) 
Selain berdasar pada dua pola penyebaran tersebut, komposisi distribusi SpA juga dapat dilakukan dengan melihat kemampuan pemerintah daerah dan masyarakat (Tabel 1). Dapat dilihat bahwa distribusi SpA mengikuti pola "ada gula ada semut" ${ }^{4}$ Kemampuan pemerintah daerah dan masyarakat, secara umum dibagi atas 4 kelompok (kuadran). Kuadran 1 adalah pemerintah dan masyarakat kaya, kuadran 2 adalah pemerintah miskin dan masyarakat kaya, kuadran 3 adalah pemerintah kaya dan masyarakat miskin, sedangkan kuadran 4 adalah pemerintah dan masyarakat miskin.

Jumlah SpA yang paling sedikit berada di kuadran 4, sedangkan sebagian besar terkonsentrasi di kuadran 1. Akan tetapi, dari keempat propinsi dengan rasio $\mathrm{SpA}$ terbanyak seperti telah disebutkan, kategori kondisi kekayaan pemerintah dan masyarakatnya berbeda. Jakarta dan Bali terletak di kuadran 1 dengan pemerintah daerah dan masyarakatnya yang kaya. DI Yogyakarta, sama halnya dengan Sulawesi Utara, terletak di kuadran 3 yang walaupun masyarakatnya miskin, tetapi pemerintahannya kaya.

Kesamaan pada keempat propinsi tersebut yaitu semuanya mempunyai Angka Kematian Bayi/AKB (per 1.000) yang rendah. ${ }^{4}$ Data seperti ini sangat penting sebagai masukan terhadap kebijakan pemerintah dalam penentuan penempatan SpA. Sebetulnya pemerintah sudah/sudah pernah mengeluarkan peraturan-peraturan, antara lain wajib kerja spesialis dan pembatasan spesialisasi anak bagi dokter perempuan. Tetapi, apakah peraturan tersebut mengatasi permasalahan? Kalau tidak, apakah ada indikator lain yang berperan?

\section{Proporsi berdasarkan jenis kelamin}

Meskipun program residensi saat ini tampaknya menunjukkan kecenderungan dominasi jumlah dokter perempuan, tetapi hingga saat ini dalam database IDAI jumlah dokter laki-laki masih dominan $(64,9 \%$ atau 1111 peserta program). Angka ini masih dapat berubah, karena terdapat $4,1 \%$ atau sejumlah 70 record yang tidak tercatat jenis kelaminnya. Namun perubahan tersebut tidak akan mengubah komposisi secara bermakna. (Gambar 3 dan 4)

Jika masih menggunakan kriteria seperti pada Tabel 1, maka penyebaran SpA menurut jenis kelamin pada wilayah tersebut masih setara. Seperti disajikan pada Tabel 2, pada setiap kuadran terlihat pola komposisi 2 banding 1 antara SpA laki-laki dibanding SpA perempuan.

\section{Pertumbuhan Dokter Spesialis Anak}

Jumlah lulusan dokter spesialis anak (SpA) di Indonesia secara fluktuatif cenderung meningkat dari tahun ke tahun dengan rerata 28 per tahun. Seperti tertera pada Gambar 5, jumlah lulusan terbanyak terjadi pada tahun 1984 yaitu sejumlah 63 orang. Pada dekade 1983-1993 jumlah lulusan terlihat stabil pada kisaran di atas 50 per tahun. Pada tahun 1994, jumlah tersebut sempat menurun tajam, akan tetapi

Tabel 1. Distribusi SpA berdasarkan kuadran kemampuan pemerintah daerah dan masyarakat

\begin{tabular}{llccc}
\hline & & \multicolumn{3}{c}{ Kemampuan Pemerintah } \\
\hline \multirow{2}{*}{ Kemampuan Masyarakat } & Pemerintah kaya & Pemerintah miskin & Jumlah \\
& & 1324 & 78 & 1402 \\
& Masyarakat kaya & 278 & 17 & 295 \\
& Masyarakat miskin & 1602 & 95 & 1697 \\
\hline
\end{tabular}

Tabel 2. Distribusi SpA di setiap kuadran berdasarkan jenis kelamin

\begin{tabular}{cccccc}
\hline & & \multicolumn{4}{c}{ Kemampuan } \\
& & Pemerintah \\
& & Lemerintah kaya & \multicolumn{3}{c}{ Pemerintah miskin } \\
\hline \multirow{3}{*}{ Kemampuan } & Masyarakat kaya & 864 & Perempuan & Laki-laki & Perempuan \\
Masyarakat & Masyarakat miskin & 174 & 405 & 54 & 22 \\
& & & 93 & 11 & 6 \\
\hline
\end{tabular}


Sari Pediatri, Vol. 8, No. 2, September 2006

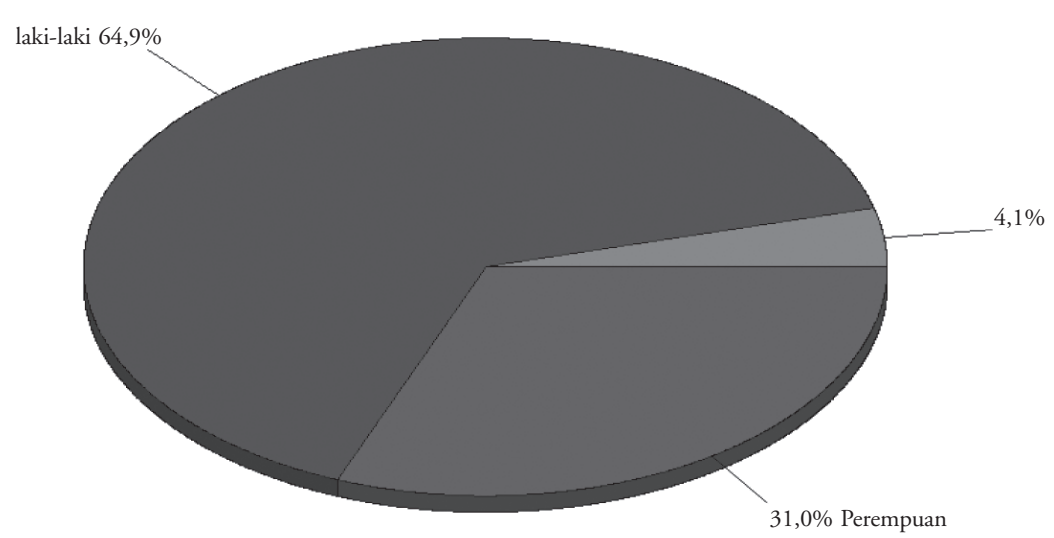

Gambar 3. Distribusi Spesialis Anak berdasarkan jenis kelamin

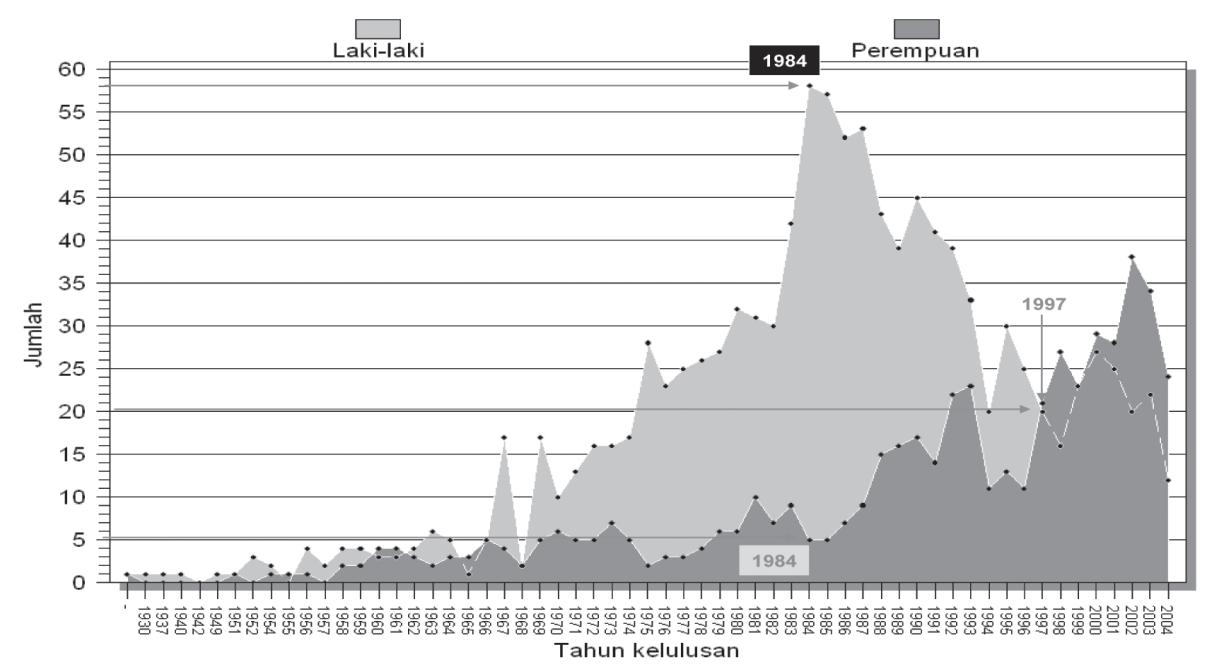

Gambar 4. Pertumbuhan SpA pertahun berdasarkan jenis kelamin

(Sumber: database IDAI)

perlahan-lahan meningkat, dan kemudian meningkat tajam pada tahun 2000. Fluktuasi ini jelas sekali dipengaruhi oleh berbagai instrumen kebijakan pemerintah, misalnya pemberlakukan kebijakan Pegawai Tidak Tetap (PTT) yang dimulai pada tahun 1992, termasuk juga dampak kebijakan desentralisasi serta penghapusan kewajiban PTT.

Perlu dicermati tentang kecenderungan semakin banyaknya spesialis anak perempuan. Hal ini merupakan fenomena universal, termasuk dalam penerimaan mahasiswa baru di Fakultas Kedokteran. Berdasarkan database IDAI, jumlah SpA perempuan memang mengalami fluktuasi, akan tetapi mulai 1997 pertambahan jumlah tersebut mulai melampaui jumlah SpA laki-laki (21:19). Pada saat yang sama, terlihat penurunan secara fluktuatif jumlah SpA lakilaki sejak tahun 1984 sampai sekarang (Gambar 4). Pertanyaan yang perlu dijawab adalah berapa jumlah spesialis yang diperlukan untuk melayani kesehatan anak di Indonesia? Apabila masih kurang, kapan dan bagaimana PSSp1IKA dapat memenuhi kebutuhannya? Apakah kualitas SpA yang dikeluarkan telah memenuhi standar dan mampu bersaing secara nasional, global? Apakah kecenderungan peningkatan salah satu jenis kelamin spesialis anak, dalam hal ini perempuan, akan memberikan dampak pada ketidakmerataan penempatan spesialis anak atau pada kebijakan? 


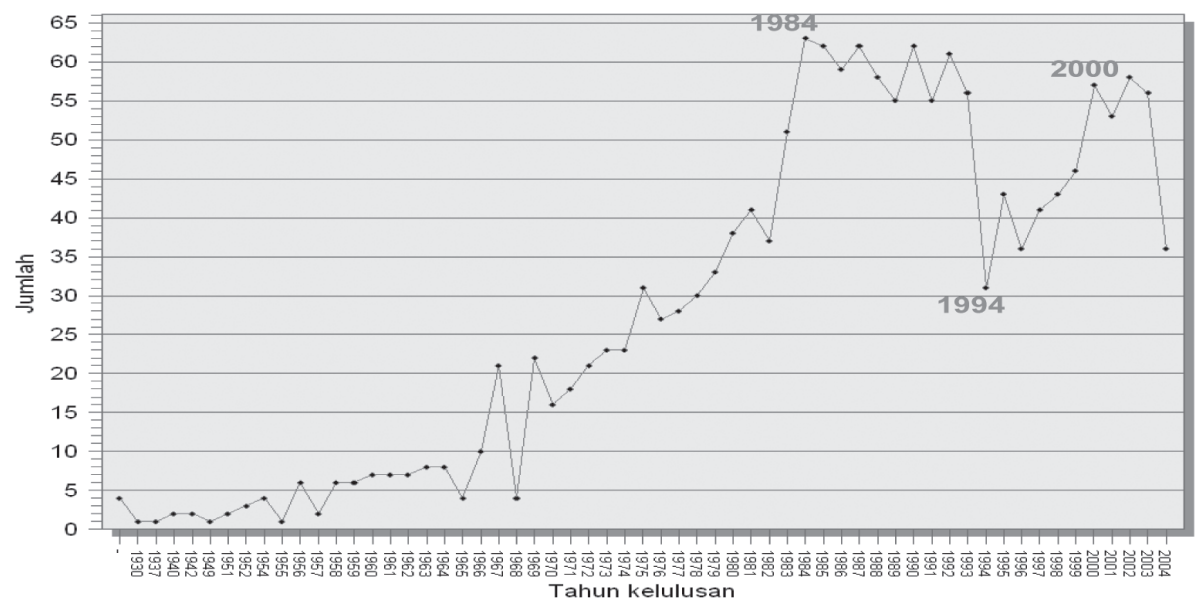

Gambar 5. Pertumbuhan Spesialis Anak per tahun (Sumber: database IDAI)

\section{Implikasi terhadap kebijakan}

\section{Implikasi terhadap kesehatan nasional}

Data yang telah disajikan jelas menunjukkan bahwa komposisi penyebaran SpA mengelompok di daerah yang masyarakat dan pemerintahannya kaya. Sementara itu, tanpa memandang penyebaran SpA berdasar pada data IDAI, status kesehatan yang tercermin dari angka kematian bayi (AKB) sangat dipengaruhi oleh keberadaan SpA. Di daerah dengan jumlah Spesialis Anak tinggi, jumlah AKB rendah. Dengan demikian, kebijakan memprioritaskan distribusi SpA di propinsi dengan AKB rendah adalah mutlak. Dengan berlakunya otonomi daerah, sudah tidak dapat ditunda, bahwa propinsi dengan AKB rendah berkewajiban memprioritaskan program kesehatan dengan upaya setempat yang spesifik, agar SpA yang ditempatkan di wilayahnya bersedia menetap. Apalagi data menunjukkan bahwa di daerah kaya yang masyarakatnya miskin, SpA masih berminat tinggal di daerah tersebut (atau mungkin oleh kerena wajib kerja?). Hal ini perlu diteliti secara lebih cermat dengan metode penelitian kualitatif, sehingga bisa ditelusuri minat SpA menetap di suatu wilayah. Temuan tersebut akan sangat diperlukan dalam menentukan kebijakan-kebijakan pemerintah daerah dalam mewujudkan good governance, khususnya di bidang kesehatan, komponen pelaksana utama meliputi pemerintah, masyarakat, dan kelompok pelaku usaha. ${ }^{5}$

\section{Implikasi terhadap pengembangan ilmu}

Penempatan SpA di daerah dan menjangkau seluruh lapisan masyarakat, dalam hubungannya dengan pengembangan ilmu adalah signifikan sejalan, diwujudkan dengan peningkatan kepedulian dan kemampuan pendidikan berbasis komunitas secara lebih profesional di bidang kesehatan anak. Terlebih lagi, dengan kondisi masyarakat yang semakin heterogen baik secara kesukuan bahkan kewarganegaraan seiring dengan perkembangan globalisasi saat ini, permasalahan kesehatanpun semakin beragam dan kompleks. Fenomena ini menuntut sensitive attention dari semua pihak, ${ }^{6}$ dan oleh karena itu pengembangan ilmu pengetahuan diharapkan dapat lebih meluas kajian dan cakupannya. Dikatakan oleh para ahli kesehatan anak bahwa future pediatricians harus mampu menyiapkan diri untuk memenuhi kebutuhan pelayanan kesehatan bagi seluruh anak dari seluruh lapisan masyarakat. ${ }^{7}$ Hal senada juga dikemukakan oleh William Cull dkk bahwa berada di tengah masyarakat bagi seorang SpA akan dapat meningkatkan community experiences and child advocacy. ${ }^{8}$ Profesionalisme kerja dan pengalaman seorang SpA harus terus ditingkatkan seiring dengan kemajuan zaman. Program pengembangan kajian keilmuan seperti ini juga akan membawa dampak positif tidak hanya dalam memahami kebutuhan pelayanan kesehatan, tetapi juga team building dan koordinasi kerja. ${ }^{?}$ 


\section{Implikasi terhadap kesejahteraan}

Dengan kemajuan hasil pembangunan saat ini diharapkan tingkat kesejahteraan masyarakat, termasuk kesehatan, akan menjadi lebih baik. Sejalan dengan hal ini, tuntutan kebutuhan pelayanan kesehatan yang profesional dan berkualitas akan sangat diperlukan, terutama dengan rasio penyebaran spesialis dengan jumlah yang memadai di setiap daerah. Perlu untuk dijadikan perhatian dan pertimbangan tentang beberapa hal yang sering menjadi concerns dalam suatu rencana strategi kebijakan penempatan dan penyebaran tenaga SpA di daerah antara lain ketakutan akan keterbatasan peluang karir dan pendidikan bagi keluarga serta potential profesional isolation. ${ }^{8}$

\section{Implikasi untuk pendidikan (competency based)}

Spesialis adalah tenaga profesional yang telah mencapai kompetensi tertentu dan profesional. Proses pendidikan, termasuk pendidikan kedokteran, merupakan proses yang dinamis dan kontinum, ${ }^{10}$ oleh karena itu sistem pendidikan berbasis kompetensi yang menekankan pada perilaku profesional ${ }^{11}$ diakui sebagai hal yang penting untuk dirancang secara terpadu. Sementara itu permasalahan kesehatan yang ada dewasa ini semakin beragam dan kompleks. Dengan penyebaran SpA ke seluruh lapisan masyarakat, pada sisi lain juga akan membawa dampak positif yaitu peningkatan kemampuan akademik dan profesional secara lebih komprehensif. Terlebih lagi, seorang SpA diharapkan untuk tidak hanya melaksanakan fungsi dalam pelayanan kesehatan, tetapi juga fungsi akademik sebagai tenaga peneliti dan pendidik. ${ }^{12}$

\section{Keterbatasan}

Database IDAI yang digunakan dalam kajian ini memiliki beberapa keterbatasan,

- Sebanyak 4,1 persen data anggota tidak tercatat jenis kelamin.

- Pencatatan wilayah (baik propinsi maupun kabupaten) tidak konsisten dan tidak up to date. Data mengenai jumlah penduduk dan struktur sosial ekonomi, yang menggunakan standar wilayah menurut BPS perlu dipertimbangkan agar dapat memberikan kontribusi yang lebih besar pada aspek kebijakan.

\section{Daftar Pustaka}

1. Pengurus Pusat Ikatan Dokter Anak Indonesia, periode 2002 - 2005: Kompendium Ikatan Dokter Anak Indonesia, Edisi kedua. Jakarta: Pengurus Pusat Ikatan Dokter Anak Indonesia; 2002.

2. Committee on Pediatric Workforce. Pediatric workforce statement. Pediatrics 1998; 102; 418-27.

3. Trisnantoro, L. Desentralisasi kesehatan di Indonesia dan perubahan fungsi pemerintahan 2001-2003, Apakah merupakan uji coba?. Gadjah Mada University; 2005

4. Badan Pusat Statistik Jakarta: Indonesia; 2003.

5. Trisnantoro, L. Aspek strategis manajemen rumah sakit antara misi sosial dan tekanan pasar. Andi Offset: Yogyakarta; 2005.

6. The future of pediatric education UU: Organizing pediatric education to meet the needs of infants, children, adolescents, and young adults in the $21^{\text {st }}$ Century [editorial]. Pediatrics 2000; 105; 163-212.

7. Committee on pediatric workforce. Culturally effective pediatric care: education and training issues. Pediatrics 1999; 103; 167 - 70

8. William LC, Beth KY, Scott AS, Richard JP. pediatric training and job market trends: result from the American Academy of Pediatrics third-year resident survey, 1997 - 2002. Pediatrics 2003; 4; 787-92.

9. Applebaum M, DeAngelis CD, McAndrews LA, Pan R. Comments of a rector panel pediatric resident education in community settings. Pediatrics 1996; (suppl 6: 1289-92.

10. Sastrowijoto, S. Kebijakan nasional pengembangan pendidikan kedokteran di Indonesia. Jurnal pendidikan kedokteran dan profesi kesehatan Indonesia. Jakarta 2005; I:1-10.

11. Savitri, T. Perumusan kompetensi dokter di Indonesia. Jurnal pendidikan kedokteran dan profesi kesehatan Indonesia. Jakarta 2005; I:11-17.

12. Kolegium Ilmu Kesehatan Anak Indonesia. Kurikulum pendidikan dokter spesialis Anak Indonesia 2000. Jakarta; 2002. 